\title{
Evaluation of knowledge, attitude and practice about research ethics and research ethics committee among post graduate residents in a tertiary care hospital in Pune, Maharashtra, India
}

\author{
Jyoti B. Gadhade, Rajesh S. Hiray*, Mukthambika Balaraj
}

Department of Pharmacology, BJGMC, Pune, Maharashtra, India

Received: 14 March 2020

Revised: 15 May 2020

Accepted: 20 May 2020

*Correspondence:

Dr. Rajesh S. Hiray,

Email: rajesh.hiray@gmail.com

Copyright: (c) the author(s), publisher and licensee Medip Academy. This is an open-access article distributed under the terms of the Creative Commons Attribution Non-Commercial License, which permits unrestricted non-commercial use, distribution, and reproduction in any medium, provided the original work is properly cited.

\section{ABSTRACT}

Background: A research ethics committee (REC) is a body responsible for ensuring that medical experimentation and human research are carried out in an ethical manner in accordance with national and international law. It is mandatory that all the research projects should be approved by EC before commencement. Recently Medical council of India has introduced mandatory online research methodology module consisting of assignments followed by mandatory exam.

Methods: A cross-sectional study using a self-administered, validated questionnaire was administered among PG residents of a tertiary care hospital in Pune having a functional ethics committee was conducted for 3 months. Number of correct and incorrect responses were noted and calculated in percentage.

Results: Total of 125 residents were enrolled and 119 subjects responded. The response rate was 95.2\%. The respondents included $59.66 \%$ clinical and $40.33 \%$ nonclinical post graduate residents. $87.39 \%$ knew the role of IEC. 95.79\% said informed consent should be mandatory document. $98.31 \%$ were aware about the institutional ethics committee (IEC) in the institution. 84.87\% think EC and research ethics should be taught as a mandatory PG module. Conclusions: Authors conclude that among the clinical and non-clinical postgraduates participating in study, there is acceptance of IECs and training in research ethics, while there are knowledge gaps in research ethics guidelines and composition of IEC. The updated MCI curriculum imbibes research curriculum but should focus on details about ethics in biomedical research. It can be initiated by workshop/awareness programmes compulsory for UG and PG students.

Keywords: Ethics committee, Research ethics, Research ethics committee

\section{INTRODUCTION}

Clinical research is defined as a systematic investigation in human beings designed to discover or contribute to a body of generalizable knowledge. ${ }^{1}$ As it involves human participants, it is the moral duty of the researchers to protect the confidentiality and dignity of the participants. Over the last decade, India has become a potential hub for clinical trials because of large pool of diverse population, treatment naïve patients, highly skilled investigators, excellent emerging technologies and last but not the least the lower drug development costs. However, globally there have been concerns about ethical and scientific implications of clinical trial globalization to the developing countries. ${ }^{2,3}$ Ethics Committees are established to safeguard the safety and rights of the participants. REC is the primary ethical regulator of clinical research. ${ }^{4}$ 
WHO in 2000 stated that "the purpose of research ethics committee (REC) in reviewing health research is to contribute to safeguarding the dignity, rights, safety and well-being of all actual or potential research participants." Therefore it is mandatory that all the research projects should be approved by REC before commencement of the study. No formal training is given about research ethics and REC to undergraduate and post graduate in their curriculum as a part of education in most of the branches of medicine except a few. ${ }^{6}$

Training in health research constitutes a very vital part of medical education. It is very much necessary to attract the students' interest towards research to improve the quality of research directly or indirectly contributing to advancement in the medical health system. Even in case of physicians, research experience is invaluable to physician's evidence based practice as it imparts skills such as literature search, collecting and analysing data and critical appraisal of evidence. ${ }^{7,8}$ Recently Medical council of India (MCI) has introduced a mandatory research methodology course consisting of 23 modules for post graduate residents followed by a mandatory examination. ${ }^{9}$ However, it has very less information about the Ethics Committee composition, diversity in its composition .

Knowledge, attitude and practices (KAP) towards principles of research is a crucial issue because. ${ }^{10}$

- $\quad$ KAP towards research varies from place to place and also from country to country

- Knowledge on Research principles is not up to the mark among health care professionals globally

- There is a need to understand the awareness about research principles specially among medical doctors as they are the future of the upcoming health development era.

It is essential to understand the KAP towards research principles among medical postgraduates to address the issues if any, so that necessary steps can be taken to tackle these problems in the future.

\section{METHODS}

The study was conducted in post graduate residents to assess the awareness about the composition and functioning of research ethics and research ethics committee of a tertiary care hospital (BJGMC and Sassoon General Hospital, Pune, Maharashtra, India).

An observational cross-sectional study using a selfadministered, self-developed validated questionnaire was administered among post graduate residents of a tertiary care hospital (BJGMC and Sassoon General Hospitals) in Pune having a functional ethics committee (EC). Content validation was used for validation of a questionnaire. For the process of validation, a questionnaire was introduced to 10 study participants providing them space for suggestions. After that, a questionnaire was given to expert of their opinion. The process of validation was completed and then it was used for the study.

This study was done in the month of September to November 2019. Approval from institutional ethics committee will be taken before initiation of the study. Strict confidentiality of participants was maintained during the study.

\section{Inclusion criteria}

Participants (post graduate residents of 1/2/3 year of residency) who were willing to participate.

\section{Exclusion criteria}

Participants (post graduate residents) not willing to participate in study.

A total of 125 participants (post graduate residents) were given the questionnaire and their response was analysed.

All participants (post graduate residents) were informed about the objectives and procedure of study before its initiation and those willing to participate were given the questionnaire.

\section{The questionnaire consisted of four parts}

- The first part concentrated on obtaining demographic data, their respective branches in medicine in MD/MS (clinical/nonclinical) and if they had prior training in research ethics

- The second part was dedicated to a self-assessment of the knowledge, attitude, and practice of each respondent regarding the awareness about the EC, that is, the frequency of meetings; total members in $\mathrm{EC}$; the issues they dealt with in everyday practice, and the respondents' views on it

- The final part consisted of questions to assess the recommendations of each respondent regarding the improvement of EC functioning.

\section{Statistical analysis}

The returned questionnaires will be checked for completeness of the data and the descriptive data will be expressed in percentages.

\section{RESULTS}

Questionnaire containing 20 questions was distributed to the participants and 20 minutes time was given to answer the questions. A total of 125 subjects were enrolled for the study. Informed consent form was obtained from all the participants of the study. Only 119 students responded to the questionnaire. The response rate of the study was 95\% The data obtained was sorted and categorized. All captured data was entered into Microsoft excel database. 
During data entry, data was checked for any error or missing data. After resolution of all issues, the database was analysed.

Figure 1 and 2 shows the demographic data of the participants. Males are slightly more than females.

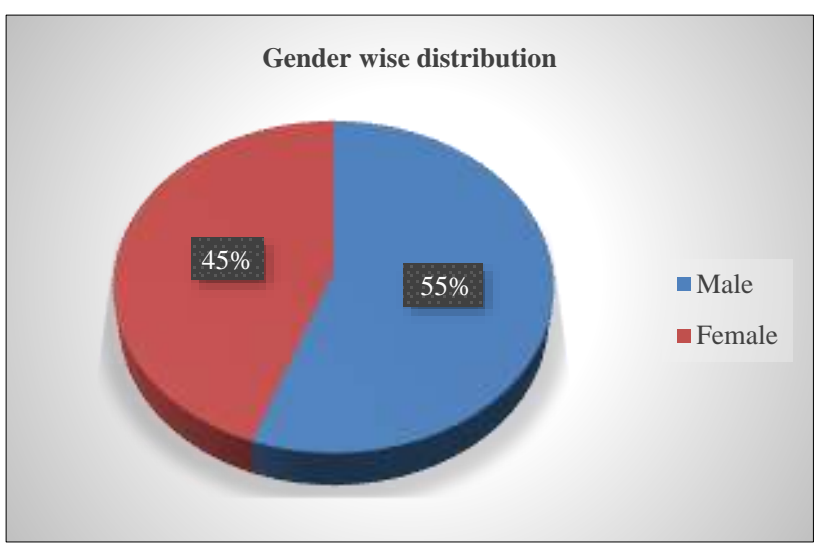

Figure 1: The gender wise distribution of the participants.

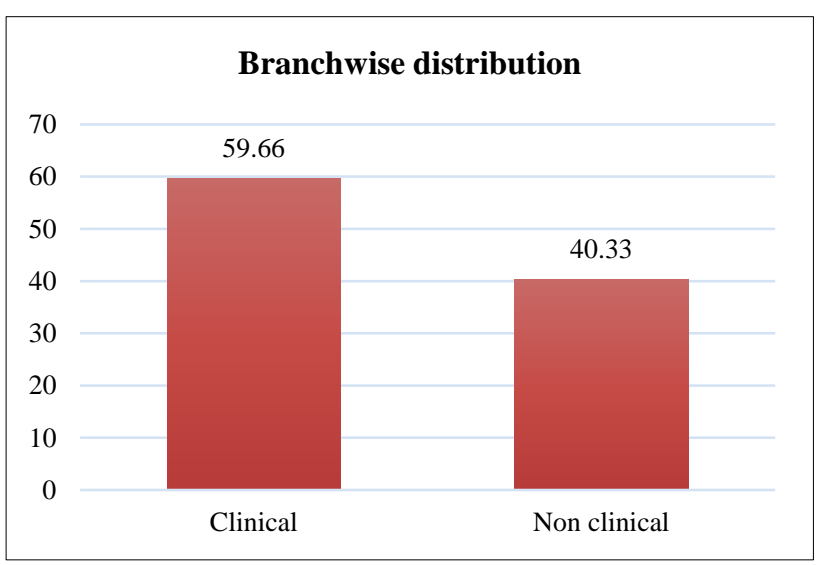

Figure 2: The branch wise distribution of the participants.

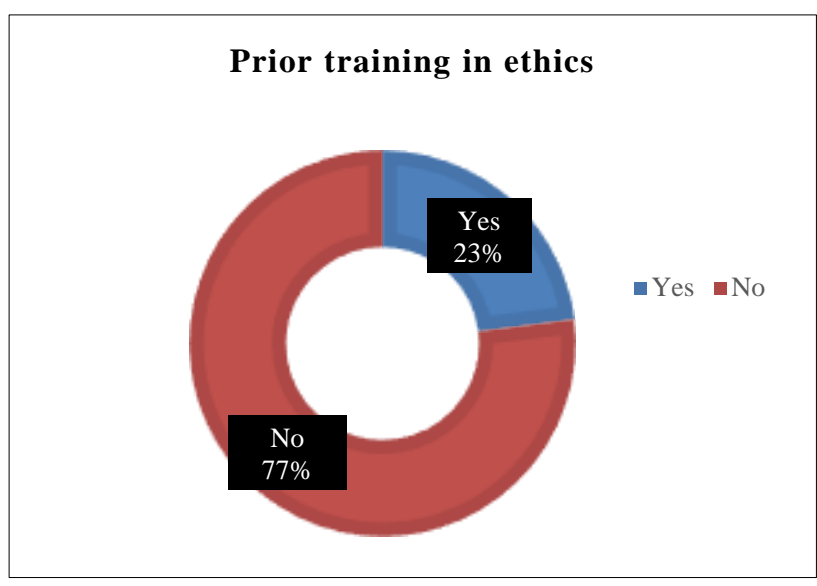

Figure 3: If the study participants had prior training in research ethics.
Around $60 \%$ participants belonged to the clinical branches whereas $40 \%$ participants were from the nonclinical branches.

Figure 3 shows 23\% participants had received prior training in ethics through workshops, conferences whereas $77 \%$ had absolutely no training in research ethics.

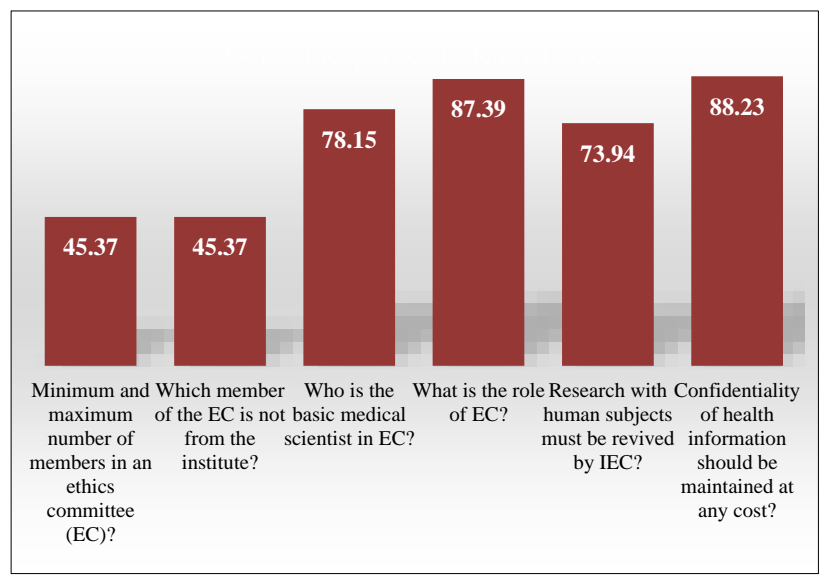

Figure 4: The correct responses to the questions pertaining to knowledge displayed in percentages.

Figure 4 shows response of the participants on questions of knowledge about research ethics and REC. Less than half of the participants answered correctly about the composition of EC. Only $45 \%$ participants knew that chairperson of EC is outside the institute. $78 \%$ responded correctly to the question of basic medical scientist of EC. $87 \%$ were aware about the role of EC in clinical research. $74 \%$ responded correctly that all the research projects must be revived by REC before its commencement. $88 \%$ said confidentiality of health information should be maintained.

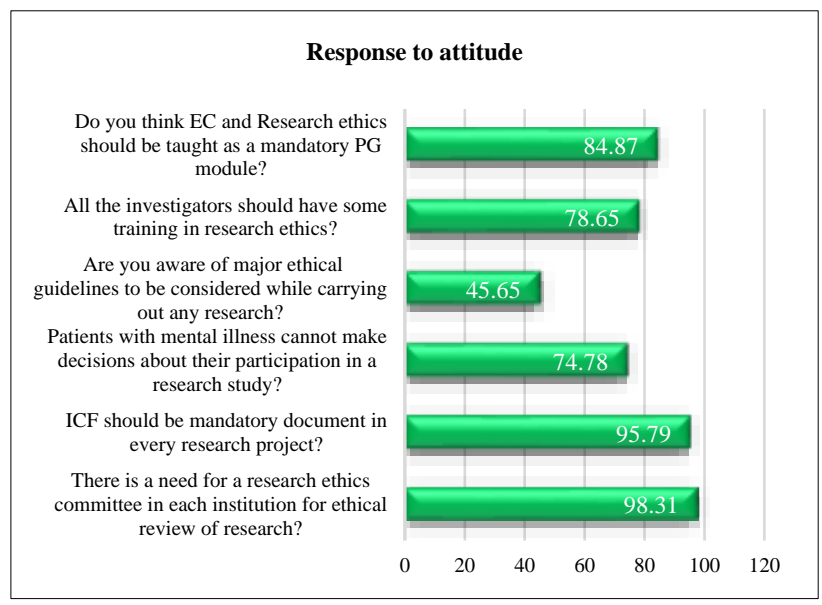

Figure 5: Response to attitude towards research ethics and research ethics committee.

Figure 5 depicts attitude towards research ethics and research ethics committee of the participants. $85 \%$ believe 
that EC and research ethics should be taught as a mandatory PG module and $79 \%$ believed that investigators must be trained in research ethics.75\% believed that patients with mental illness cannot make decisions about their participation in a study. Majority of the participants i.e. $96 \%$ said that ICF should be a mandatory document in every research project. Less than half of the participants were aware of the major ethical guidelines that are considered for conducting research like ICMR, GCP guidelines. $81 \%$ had idea about conflict of interest.

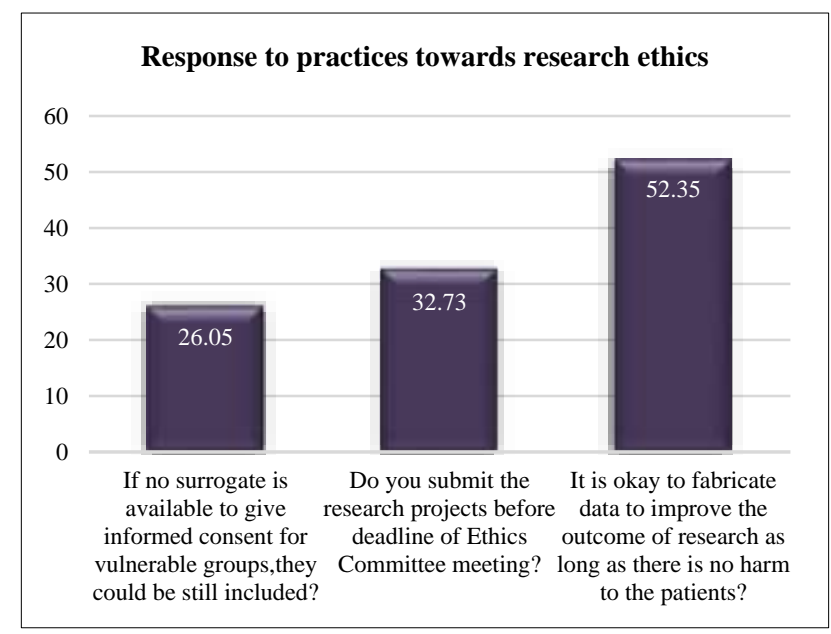

Figure 6: Response to practices towards research ethics.

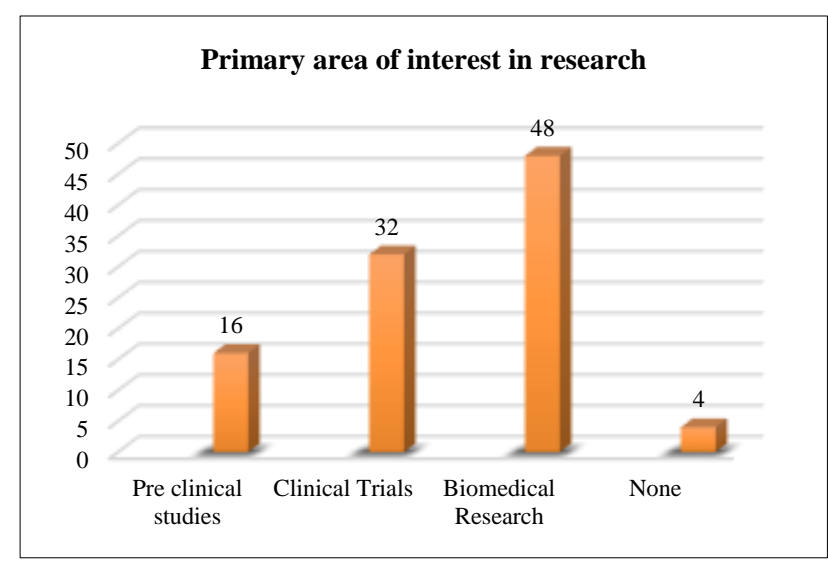

Figure 7: The primary areas of interest in research of the study participants.

Figure 6 shows $26 \%$ of the respondents responded that if no surrogate is available to give informed consent for vulnerable groups, they shall be included. Only $33 \%$ of the participants know about the deadlines for submitting research protocols to the ethics committee. This might put the researchers in administrative hurdles thus causing subsequent loss of interest in research. 52\% of participants believe that it is okay to fabricate data to improve the outcome of research as long as there is no harm to the patients.

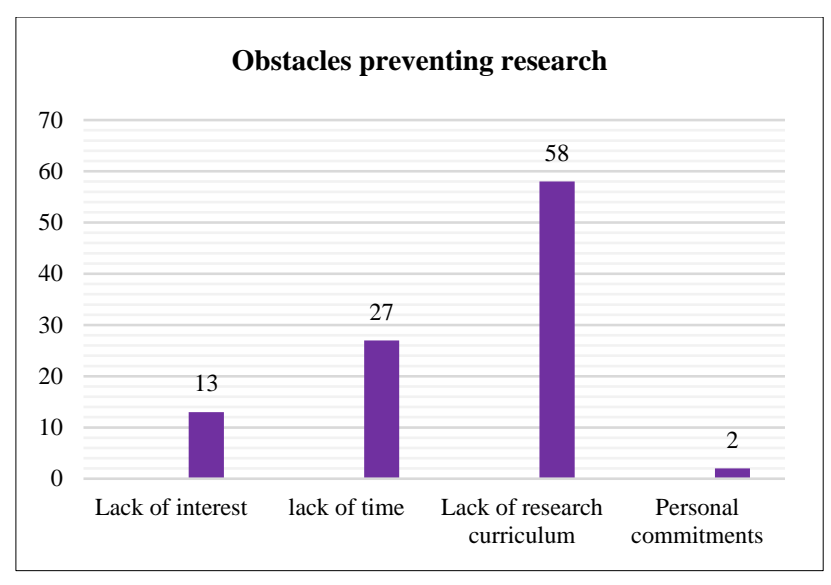

Figure 8: Obstacles preventing research.

Figure 7 depicts the primary areas of interest in research of the study participants. $16 \%$ are interested in preclinical studies, $32 \%$ have shown their interest in clinical trials, $48 \%$ in biomedical research thus stressing on the need for training in research ethics and $4 \%$ are not interested in neither of them.

Figure 8 represents the various barriers impeding research. $13 \%$ say that lack of interest is one of the barriers, $27 \%$ believe that lack of time due to hectic schedule and duties in the hospital whereas $48 \%$ responded by saying that major obstacle preventing them from carrying out research is the lack of curriculum which indirectly points out to inclusion of compulsory extensive training of the doctors in research ethics. $2 \%$ of the respondents said that personal commitments are responsible for impeding research.

The study also revealed the various sources of learning about ethics committee and REC like journals, through workshops, conferences, etc. Majority (56.3\%) reported that the major source of learning about EC was through workshops followed by conferences $(51.26 \%)$ followed by journals $(38.65 \%)$, lectures $(28.57 \%)$.

\section{DISCUSSION}

Results of this study were similar to that of Munoli et al where $76 \%$ had no prior training in ethics. ${ }^{11}$ It had more females compared to males which is in contrast to this study where there are more male participants.

This study results are similar to study conducted by Mallela et al and Munoli et al where $>50 \%$ of participants responded correctly for questions on informed consent, institutional ethics committee and about 8-35\% participants had knowledge about various ethical guidelines. ${ }^{12}$ In Mohammad et al, majority of the residents and faculty were of the opinion that dean is the chairman of IEC. ${ }^{13}$ Majority of the residents thought that all studies involving human beings should not be reviewed by IEC which contradicts this study where $74 \%$ residents responded that it should be reviewed by EC. Shende et al, 
$25(25.51 \%)$ PG residents were aware that chairperson should not be from the institution which is much less than this study where $43 \%$ of the participants were aware. ${ }^{14}$

Demour et al study showed that $60.3 \%-88.7 \%$ of participants were aware of IC in clinical research whereas in this study $96 \%$ of the participants were aware of ICF which is slightly higher. ${ }^{15}$ The vast majority of participants were aware of confidentiality of the individuals' data which is similar to this study. $27 \%$ of participants believed that in the absence of a surrogate the vulnerable groups could give IC which is almost similar to this study (26\%). Mallela et al and El-Dessouky et al reported that $46 \%$ and $40 \%$ of participants respectively believed that certain vulnerable groups could provide IC to participate in research. ${ }^{16} 68 \%$ believed that If no surrogate is available to give informed consent for vulnerable groups, they could still be included in contrast to $7 \%$ in study by El-Dessouky et al. A study by Bhowmick et al stated that formal mandatory training is required to ensure safety of the subjects participating in clinical trials. ${ }^{4} \mathrm{Al}$ Demour et al, $82.7 \%$ of participants thought that investigators should have some training in research ethics which is slightly higher than the findings of this study where $78.65 \%$ participants stated that formal

mandatory training is required according to Madhavrao et al, more than $65 \%$ of medical postgraduates had keen interest in carrying out research projects in future mainly in clinical trials. ${ }^{17}$ It was also found that, more than half of the study participants had opined as 'lack of time' as the main obstacle preventing doing research. Lack of time was seen as a significant barrier to pursuing research during medical school due to the busy curriculum according to Siemens et al. ${ }^{18}$ This factor results in a decreased number of medical students interested in participating in research.

Madhavrao et al study stated that more than $65 \%$ of medical postgraduates had keen interest in carrying out research projects in future mainly in clinical trials whereas majority (48\%) of this study participants were interested in biomedical research and $32 \%$ in clinical trials.

\section{CONCLUSION}

This study concluded that there was good knowledge and attitude but poor practices towards principles of research among medical postgraduates. Though they had positive attitude towards research, they failed to transform their knowledge and attitude in actual practices due to lack of time and lack of research curriculum. There is a necessity to encourage postgraduate students to carry out research through provision of mandatory workshops during their postgraduate training program previous PG curriculum had certain loopholes and lacked in training aspect of ethics. The updated curriculum by MCI imbibes research curriculum but should focus on details about ethics in biomedical research. Pre-conference workshops should have compulsory pre workshops on research ethics for newly joined residents.

Funding: No funding sources

Conflict of interest: None declared

Ethical approval: The study was approved by the Institutional Ethics Committee

\section{REFERENCES}

1. Borovečki A, ten Have H, Orešković S. Education of ethics committee members: Experiences from Croatia. J Med Ethics. 2006;32:138-42.

2. Glickman SW, McHutchison JG, Peterson ED, Cairns CB, Harrington RA, Califf RM, et al. Ethical and scientific implications of the globalization of clinical research. N Engl J Med. 2009;360:816-23.

3. Nundy S, Gulhati CM. A new colonialism? Conducting clinical trials in India. $\mathrm{N}$ Engl $\mathrm{J}$ Med. 2005;352:1633-6.

4. Bhowmick S, Banerjee K, Sikdar S, Chatterjee TK. An evaluation of knowledge, attitude, and practice of institutional ethics committee members from eastern India regarding ethics committee functioning and pharmacovigilance activities conducted during clinical trials: a pilot study. Perspect Clin Res. 2014;5:115-20.

5. World Health Organization. WHO Special Programme for Research and Training in Tropical Diseases (TDR). Operational Guidelines for Ethics Committees that Review Biomedical Research. World Health Organization; 2000.

6. World Health Organization. Operational guidelines for ethics committees that review biomedical research. Geneva; 2000: 4-5.

7. Madhavrao C, Menon R, Babu S. Knowledge attitude and practices towards principles of research among medical postgraduates in a teaching tertiary care centre. Int J Cur Res Rev. 2016;8(2):1-6.

8. Gore AD, Kadam YR, Chavan PV, Dhumale GB. Application of biostatistics in research by teaching faculty and final year postgraduate students in colleges of modern medicine: a cross-sectional study. Int J Appl Basic Med Res. 2012;2:11-6.

9. Basic Course in Bio-medical Research. MCI in partnership with ICMR. Available at: https://swayam.gov.in/nd1_noc19_ge33. Accessed on 12 February 2020.

10. Zambudio AR, Gascón FS, Moro LG, Fernández MG. Research training during medical residency (MIR). Satisfaction questionnaire. Rev Esp Enferm Dig. 2004;96:695-704.

11. Munoli S, Niveditha G, Deepthi R. Knowledge, attitude and practice of research ethics among medical faculty in a teaching hospital. Int $\mathrm{J}$ Basic Clin Pharmacol. 2017;6:913-8.

12. Mallela KK, Walia R, Devi TM, Das M, Sepolia S, Sethi P. Knowledge, Attitudes and Practice about Research Ethics among Dental Faculty in the North India. J Inter Oral Health. 2015;7(2):52-6. 
13. Mohammad M, Ahmad F, Rahman SZ, Gupta V, Salman T. Knowledge, attitudes and practices of bioethics among doctors in a tertiary care government teaching hospital in India. J Clinic Res Bioeth. 2011;2:118.

14. Shende SS, Tilak S, Bhalchandra A, Das R, Gupta S, Vaid T, et al. Ethics committee awareness amongst the medical teachers and post graduate residents in a medical college. Int J Current Med Pharma Res. 2017;3(11):2592-4.

15. Al Demour S, Alzoubi KH, Alabsi A, Al Abdallat S, Alzayed A. Knowledge, awareness, and attitudes about research ethics committees and informed consent among resident doctors. Int $\mathrm{J}$ Gen Med. 2019;12:141-5.

16. El-Dessouky HF, Abdel-Aziz AM, Ibrahim C, Moni M, Abul Fadl R, Silverman H. Knowledge, awareness, and attitudes about research ethics among dental faculty in the middle east: a pilot study. Int $\mathbf{J}$ Dent. 2011;2011:694759.

17. Madhavrao C, Mythili BK, Rema MN, Sharath BK, Prathab AA. Knowledge attitude and practices towards principles of research among medical postgraduates in a teaching tertiary care centre. Int $\mathrm{J}$ Cur Res Rev. 2016;8(2):4-9.

18. Siemens DR, Punnen, S, Wong J, Kanji N. A survey on the attitudes towards research in medical school. BMC Med Educ. 2010;10(1):4.

Cite this article as: Gadhade JB, Hiray RS, Balaraj M. Evaluation of knowledge, attitude and practice about research ethics and research ethics committee among post graduate residents in a tertiary care hospital in Pune, Maharashtra, India. Int J Basic Clin Pharmacol 2020;9:1084-9. 